\title{
Hypoglycaemic Property of Nutraceuticals
}

\section{Mohammad Emdadul Haque ${ }^{1}$, Quazi Safayetullah ${ }^{2}$, Monira Ahsan ${ }^{3}$ and Sheikh Nazrul Islam²}

\author{
${ }^{1}$ Department of Dermatology, Dhaka Medical College and Hospital, Dhaka-1000, Bangladesh \\ 2Institute of Nutrition and Food Science, University of Dhaka, Dhaka-1000, Bangladesh \\ ${ }^{3}$ Department of Pharmacetical Chemistry, Faculty of Pharmacy, University of Dhaka, Dhaka-1000, Bangladesh
}

\begin{abstract}
Hypoglycemic property of four nutraceuticals named - black cumin, garlic, methi and karela has been investigated on an alloxan induced diabetic rat model. Glibenclamide was used as positive control and normal saline was used as negative control. Serum glucose levels of normal and diabetic induced rats were estimated by Glucose Oxidase method using a kit, and it were $4.33 \pm 0.43 \mathrm{mmol} / \mathrm{L}$ and $8.27 \pm 0.45 \mathrm{mmol} / \mathrm{L}$ respectively. The alloxan induced diabetic rats were grouped into six, which were then treated with the four nutraceuticals and two controls. Treatment was given orally everyday for 28 days. Serum glucose level was analysed every 7 day intervals. It was observed that lowering of glucose level was significant $(P=0.01)$ for every 7 day treatment period. All of the nutraceuticals reduced the serum glucose level nearly to the normal value within 28 days. The rate of lowering of the glucose level was found to vary with the nutraceuticals. Garlic was found to be most active like the glibenclamide. The next active one was black cumin followed by methi and karela. The study conclude that nutraceuticals possess significant hypoglycemic property.
\end{abstract}

Key words: Hypoglycaemia, Nutraceuticals, Black cumin, Garlic, Methi, Karela.

\section{INTRODUCTION}

Nutraceuticals are medical foods that are used in prevention and treatment of many ailments. ${ }^{1,2}$ Nutraceuticals have been reported to have a versatile spectrum of medicinal properties against viruses ${ }^{3}$ to cardiovascular disorders. ${ }^{4}$ They are strong antimicrobial agents, even effective against many drug resistant strains. ${ }^{5}$ Some nutraceuticals have, even, been claimed to be effective in prevention and/or management of HIV/AIDS. ${ }^{6}$ Although, some nutraceuticals have long been traditionally used in the treatment of diabetes, a very few scientific reports on their hypoglycaemic activity in animal model are

Correspondence to: SK. Nazrul Islam

Tel: +880 2 96619-73 ext 8418; Fax: +880 2 8615583;

E-mail: snislam@bangla.net, nazrul05monira@yahoo.com

Dhaka Univ. J. Pharm. Sci. 6(2): 105-107, 2007 (December) available. $^{7,8}$ We, therefore, report here the hypoglycaemic activity of four nutraceuticalsNigella stiva Linn, Allium sativum Linn, Trigonella foenum graecum Linn (Fenugreek) and Momordica charantia on an alloxan induced diabetic rat model.

\section{MATERIALS AND METHODS}

Animal model. Fifty Long Evan's rats of 180200 gm weight that were procured from ICDDR,B, Dhaka were housed in standard condition. They were fed with pellet diet and water for three day. Fasting blood glucose level of each rat was determined. A single dose $(120 \mathrm{mg} / \mathrm{kg}$ body weight) of alloxan tetrahydrate (Sigma Chemical Co., USA) was injected intraperitoneally to each of the rats. After 72 hours of injection, fasting blood glucose level was determined. Five rats did not respond to alloxan and 
3 rats died. Finally forty-two alloxan induced diabetic rats were grouped into six for treatment with four nutraceuticals, glibenclamide and normal saline. The rats were treated orally everyday for 28 days with the dose mentioned in the Table 1 . Serum glucose level was determined every 7day time interval.

Preparation of nutraceuticals. The volatile oil of Nigella sativa Linn (black cumin) was prepared by steam distillation as described by Islam et l. $^{7}$ It yielded $0.4 \% \mathrm{v} / \mathrm{v}$. Aqueous extract of garlic (Allium sativum Linn) was prepared by crushing peeled garlic cloves with distilled water followed by filtration and centrifugation. It yielded $1 \mathrm{~g} / \mathrm{ml}$ extract. Similarly aqueous extracts of methi and karela were prepared that yielded $0.5 \mathrm{~g} / \mathrm{ml}$ and $1.6 \mathrm{~g} / \mathrm{ml}$ concentration respectively.

Glucose estimation. Fasting blood samples were collected by tail bleeding of each rat at specified time schedules. Blood samples were centrifuged at 3000 rpm for 15 minutes to separate the serum. Serum glucose level was estimated by Glucose Oxidase method using a glucose estimation kit (Human. Germany) using of ELISA plate reader (Labsystems, MultiskanEX, Finland).
Statistical analysis. SPSS software package (version 11.5, SPSS Inc. Chicago, USA) was used to analyse the data. Descriptive statistics were calculated for all variables. Values were expressed as percentage and mean \pm SD. Comparison of the serum glucose levels in seven day interval was performed by independent sample t-test (i.e. unpaired 't' test).

\section{RESULTS AND DISCUSSION}

Out of 50 rats taken, five rats did not respond to alloxan treatment and three rats died; therefore, the final results were analysed on 42 rats. The serum glucose levels of both the experimental and control rats were determined every seven day time interval.

Table 1 shows the glucose lowering effect of nutraceuticals on the alloxan induced diabetic rat model. It was noted that all the nutraceuticals were significantly $(\mathrm{P}<0.01)$ effective in lowering of blood glucose in diabetic rats. It was shown that the nutraceuticals continuously reduced the glucose level and made it to nearly normal level within 28 days of treatment. The rate of glucose lowering was found to vary with the nutraceuticals. Garlic was found to be

Table 1. Hypoglycemic action of Nigella sativa, Garlic, Methi, Kerala on alloxan induced diabetes rat model.

\begin{tabular}{|c|c|c|c|c|c|c|}
\hline \multirow[t]{2}{*}{ Nutraceuticals } & \multicolumn{6}{|c|}{$\begin{array}{l}\text { Serum glucose level }(\mathrm{mmol} / \mathrm{L}) \\
\text { Mean }+\mathrm{SD}\end{array}$} \\
\hline & Dose & 0 day $^{\mathrm{a}}$ & $7^{\text {th }}$ day $^{\text {b }}$ & $14^{\text {th }}$ day $^{\mathrm{c}}$ & $21^{\text {st }}$ day $^{\mathrm{d}}$ & $28^{\text {th }}$ day $^{\mathrm{e}}$ \\
\hline Volatile oil of Nigella sativa ${ }^{1}$ & $25 \mu \mathrm{l}$ & $8.39 \pm 0.47$ & $7.02 \pm 1.39$ & $6.40 \pm 1.09$ & $6.06 \pm 0.93$ & $5.52 \pm 0.97 * *$ \\
\hline Aqueous extract of garlic ${ }^{2}$ & $500 \mu \mathrm{l}$ & $8.13 \pm 0.15$ & $6.03 \pm 0.58$ & $5.66 \pm 0.34$ & $5.49 \pm 0.34$ & $5.02 \pm 0.38 * *$ \\
\hline Aqueous extract of methi ${ }^{3}$ & $500 \mu \mathrm{l}$ & $8.12 \pm 0.14$ & $7.35 \pm 0.55$ & $6.60 \pm 0.56$ & $6.08 \pm 0.35$ & $5.94 \pm 0.71 * *$ \\
\hline Aqueous extract of karala ${ }^{4}$ & $500 \mu \mathrm{l}$ & $8.05 \pm 0.71$ & $7.49 \pm 0.96$ & $7.04 \pm 1.04$ & $6.53 \pm 1.00$ & $5.94 \pm 0.71^{* *}$ \\
\hline Glibenclamide $^{5}$ & $2.5 \mathrm{mg}$ & $8.52 \pm 0.42$ & $6.60 \pm 1.29$ & $4.83 \pm 2.09$ & $4.80 \pm 1.82$ & $4.34 \pm 0.77 * *$ \\
\hline Normal saline $^{6}$ & $100 \mu \mathrm{l}$ & $8.05 \pm 0.71$ & $7.99 \pm 0.84$ & $8.05 \pm 0.72$ & $7.98 \pm 0.77$ & $8.01 \pm 0.77$ \\
\hline \multicolumn{7}{|l|}{ ** Significance $\mathrm{P}<0.01$} \\
\hline $1^{\mathrm{ab}}: \mathrm{t}=3.347, \mathrm{p}=0.015$ & \multicolumn{2}{|c|}{$1^{\mathrm{ac}}: \mathrm{t}=5.66, \mathrm{p}=0.001$} & \multicolumn{2}{|c|}{$1^{\text {add }}: t=7.85, p=0.000$} & \multicolumn{2}{|c|}{$1^{\text {ae }}: t=9.726, p=0.000$} \\
\hline $2^{\mathrm{ab}}: \mathrm{t}=12.28, \mathrm{p}=0.000$ & \multicolumn{2}{|c|}{$2^{\mathrm{ac}}: \mathrm{t}=21.6, \mathrm{p}=0.000$} & & \multicolumn{2}{|c|}{$2^{\mathrm{ae}}: \mathrm{t}=21.215, \mathrm{p}=0.000$} \\
\hline $3^{\mathrm{ab}}: \mathrm{t}=4.48, \mathrm{p}=0.004$ & \multicolumn{2}{|c|}{$3^{\mathrm{ac}}: \mathrm{t}=8.109, \mathrm{p}=0.000$} & \multirow{2}{*}{\multicolumn{2}{|c|}{$3^{\text {ad }}: t=20.02, p=0.000$}} & \multicolumn{2}{|c|}{$3^{\mathrm{ae}}: \mathrm{t}=20.482, \mathrm{p}=0.000$} \\
\hline $4^{\mathrm{ab}}: \mathrm{t}=4.13, \mathrm{p}=0.006$ & \multicolumn{2}{|c|}{$4^{\mathrm{ac}}: t=5.05, p=0.002$} & \multirow{2}{*}{\multicolumn{2}{|c|}{$4^{\text {add }}: \mathrm{t}=6.99, \mathrm{p}=0.000$}} & \multicolumn{2}{|c|}{$4^{\mathrm{ae}}: \mathrm{t}=15.427, \mathrm{p}=0.000$} \\
\hline $5^{\mathrm{ab}}: \mathrm{t}=5.55, \mathrm{p}=0.001$ & \multicolumn{2}{|c|}{$5^{\mathrm{ac}}: \mathrm{t}=6.103, \mathrm{p}=0.001$} & & & \multicolumn{2}{|c|}{$5^{\mathrm{ae}}: t=9.5, p=0.000$} \\
\hline $6^{\mathrm{ab}}: \mathrm{t}=0.699, \mathrm{p}=0.528$ & \multicolumn{2}{|c|}{$6^{\mathrm{ac}}: \mathrm{t}=0.105, \mathrm{p}=0.919$} & \multicolumn{2}{|c|}{$6^{\text {ad }}: t=0.66, p=0.53$} & \multicolumn{2}{|c|}{$6^{\text {ae }}: t=0.34, p=0.742$} \\
\hline
\end{tabular}

most effective like glibenclamide that lowered glucose level to normal limit within 14 days of treatment. The next active one was black cumin followed by methi and karela that lowered glucose level close to normal value in 28 days of treatment. The negative control (saline) gave predicted outcome.

It was observed that rate of glucose lowering was found to be linear and equivalent for all of the 
nutraceuticals during the seven day time interval, which were significant $(\mathrm{p}<0.01)$ from one interval to other. The serum glucose levels for Nigella sativa Linn were $8.39 \pm 0.47 \mathrm{mmol} / \mathrm{L}, 7.02 \pm 1.39 \mathrm{mmol} / \mathrm{L}$, $6.40 \pm 1.09 \mathrm{mmol} / \mathrm{L}, 6.06 \pm 0.93 \mathrm{mmol} / \mathrm{L}$ and $5.52 \pm$ $0.97 \mathrm{mmol} / \mathrm{L}$ ) on 0 day, 7 day, 14 day, 21 day and 28 day, respectively. Similarly it were $8.13 \pm 0.15,6.03 \pm$ 0.58, $5.66 \pm 0.34,5.49 \pm 0.34,5.02 \pm 0.38 \mathrm{mmol} / \mathrm{L}$ for garlic; $8.12 \pm 0.14,7.35 \pm 0.55,6.60 \pm 0.56,6.08$ \pm 0.35 and $5.94 \pm 0.71 \mathrm{mmol} / \mathrm{L}$ for methi; $8.05 \pm 0.71$, $7.49 \pm 0.96,7.04 \pm 1.04,6.53 \pm 1.00$ and $5.94 \pm$ $0.71 \mathrm{mmol} / \mathrm{L}$ for karela (Table 1 ). The rate of glucose lowering was found to be faster for garlic, it became normal within 14 days and then it turned up steady.

Diabetes is one of the major public health problems in the world. It is increasing in developing countries like Bangladesh. The common therapies used for diabetes are injectable insulin, oral hypoglycaemic agents, exercise and balance diet with other symptomatic treatments. However till today no effective treatment in complementary system of medicine has yet been established for treating this disease. Therefore, attempt to find out effective antidiabetic agents with acceptable safety profile is being carried out worldwide. In line of this effort, we investigated four traditionally used nutraceuticals for their hypoglycaemic activity on diabetic rat model.

Results of the present study indicate that all of nutraceuticals were potentially effective in lowering of blood glucose level in diabetic rats. It was shown that nutraceuticals tested gradually reduced blood glucose in diabetic rats and made it to normal level within 28 days of treatment. Of the nutraceuticals, garlic was found to be the most effective. It was as effective as glibenclamide in term of lowering of glucose level; both made the glucose level normal within 14 days of treatment. The next active agent was black cumin followed by methi and karela that made glucose level near to normal value within 28 days of treatment. Hypoglycemic property of garlic, black cumin and kerala has also previously been reported in man and animal model. ${ }^{8,9,10}$

The anti-diabetic principle of Nigella stiva, Allium sativum, Trigonella foenum graecum and Momordica charantia would be of indicative for effective use of nutraceuticals in the management of diabetes. Long term treatment with large number of animals should be conducted before taking any attempt of clinical trial.

\section{REFERENCES}

1. Biro, G. 1995. The use of results of scientific nutrition research in clinical practice. Orv Hetil, 136(19), 979-983.

2. Kottke, M.K. 1998. Scientific and regulatory aspects of nutraceutical products in the United States. Drug Dev. Ind. Pharm, 24(12), 1177-1195.

3. Abdullah, T.H., Kandil, O., Elkadi, A. and Carter, J. 1988. Garlic revisited: therapeutic for the major disease of our times ? J. Natl. Med. Assoc. 80(4), 439-445.

4. Tahir, K.E.H. and Ageel, A.R.M. 1994. Effect of the volatile oil of Nigella sativa on the arterial blood pressure and heart rate of the guinea pig. Saud. Pharm. J. 2(4), 163-168.

5. Islam, S.N. and Ahsan. M. 1999. Drug resistance in shigellosis and efficacy of natural products as an anti shigella agents. Pub Health J. 1,2 , 20-30.

6. Allard, J.P., Aghdassi, E., Chau, J., Salit, I. and Walmsley, S. 1998. Oxidative stress and plasma antioxidant micronutrients in humans with HIV infection. Am. J. Clin. Nutr. 67, 143-147.

7. Islam, S.N., Begum, P., Ahsan, T., Huque, S. and Ahsan, M. 2004. Immunosuppressive and cytotoxic properties of Nigella sativa. Phytother Res. 18, 395-398.

8. Zuhair, H.H., EL-Sayed, M.I. and Sadek, M.A. 1996. Hypoglycemic effect of the volatile oils of Nigella sativa and Allium sativum and their glipizide on alloxan diabetic rats. Bull Fac. Pharm. 34(2), 101-106.

9. Sheela, C.G., Kumud, K. and Augusti, K.T. 1995. Antidiabetic effects of onion and garlic sulfoxide amino acids in rats. Planta. Med. 61(4), 356-357.

10. Welihida, J., Arvidson, G., Gylfe, E., Hellman, B. and Karlsson, E. 1982. The insulin-releasing activity of the tropical plant momordica charantia. Acta Biol. Med. Germ. 41, 12201240. 